\title{
LVIII. Microscopic observation on the perforation of the capillaries by the corpuscles of the blood, and on the origin of mucus and pus-globules
}

\section{Augustus Waller M.D.}

To cite this article: Augustus Waller M.D. (1846) LVIII. Microscopic observation on the perforation of the capillaries by the corpuscles of the blood, and on the origin of mucus and pus-globules, Philosophical Magazine Series 3, 29:195, 397-405, DOI: $10.1080 / 14786444608645527$

To link to this article: http://dx.doi.org/10.1080/14786444608645527

Published online: 30 Apr 2009.

Submit your article to this journal $\sqsubset$

Џ Article views: 9

View related articles $₫$ 
taken with substances whose per-centages of water and nitrogen had been ascertained.

Because theoretical equivalents have been employed in conditions unequally suited to digestion. The same food, coarse or fine, fresh or prepared for easy digestion, yields unequal measures of nutrition.

Because the conditions, whether exposed to the open air or protected in stalls, whether subjected to labour of uniform severity, or allowed the free range of pastures, have not been made alike.

Finally, because, as above intimated, some animals by nature differ greatly from others, in the facility with which fat and muscle are developed, even when the circumstances are precisely the same.

LVIII. Microscopic Observations on the Perforation of the Capillaries by the Corpuscles of the Blood, and on the Origin of Mucus and Pus-globules. By Augustus W WLLER, M.D.*

[Continued from p. 287.]

T $\mathrm{N}$ the preceding Number of this Journal I have already given 1 a brief outline of some observations respecting the manner in which the white corpuscles of the blood are seen to leave the interior of the capillary vessels. As this subject is intimately connected with the formation or origin of the globules found in mucus and purulent matter, it deserves a close and strict investigation.

In the first place, we must bear in mind that the blood consists of transparent fluid parts containing two kinds of particles in suspension; the one of a red colour and a flattened disc-like shape, and the other nearly transparent and spherical. The examination of the tongue of the frog, or of any other transparent part of a living animal, shows these globules and corpuscles generally circulating together through the capillaries.

The examination of mucus and purulent matter shows that they contain great quantities of globules, which are exactly similar to the spherical corpuscles found in the blood. In all these instances these particles are of a spherical form, transparent or whitish, granulated, and about the size of $\frac{1}{10}$ th of a millimetre. In acetic acid they contract, in the alkalies they are quickly broken up, in water they swell and are disaggregated into separate minute granules.

The corpuscles of blood in the mammiferæ and in the frog are found to be of about the same size as in man.

In proof of what I have stated respecting the similarity of

* Communicated by the Author. 


\section{Dr. Waller on the Origin of Mucus and Pus-globules.}

these bodies in pus, mucus and in the blood, I may mention that I have before me drawings of mucus and purulent globules, and of the corpuscles obtained from man and from some of the cold-blooded animals. All these drawings have been carefully executed under the camera lucida, at different times; and they resemble each other so closely as to render it impossible to give any distinctive character to recognise one from the other.

In consequence of this striking resemblance, observers have already supposed that the corpuscles of the blood give rise to those found in mucus and pus, and that these are simply corpuscles extravasated or filtered from the blood. An important observation has moreover corroborated this theory, namely that of the accumulation of the corpuscles at the inner sides of vessels which are subjected to any prolonged irritation. 'This theory has principally been known in this country from the talented observations of $\mathrm{Mr}$. W. Addison.

On the other hand, it has appeared to other physiologists so improbable to suppose the perforation of the capillary vessels by the corpuscles, that they have come to the conclusion that they are not derived firom the blood, but, like semen or milk, are formed on the secreting surface, in virtue of some plastic power of the fluids which are effused upon it. This opinion is maintained, with some modifications of trifling import, by Müller, Autenreith, Donné, \&c.

My observations respecting the almost exclusive accumnlation of the corpuscles in the vessels of the frog's tongue which are most exposed to irritation, was already an advance in the inductive proof of the first theory; but it is especially the observations at the end of the preceding paper which give the crowning evidence in its favour. I have already had the satisfaction to find that they have been confirmed by other observers to whom I have shown them. On my own part, I have repeated them in very numerous instances with invariable success.

Let us now examine the admirable manner in which nature has solved this apparent paradox, of eliminating, from a fluid circulating in closed tubes, certain particles floating in it, without causing any rupture or perforation in the tubes, or allowing the escape of the red particles, which are frequently the smaller of the two, or that of the fluid part of the blood itself. In order to allow less latitude to the imagination, I will in the first place describe faithfully, from a number of others, one or two complete observations, as I have noted them down at the time of experimenting.

Obs. 1.-A frog's tongue was secured in the usual manner. 
The capillaries became rapidly distended with blood, and the colour of the entire organ was darker from this injection. After exposure to the air for two or three hours it was again examined : the appearance presented by its inferior surface is represented in Plate Il. fig. 1. The capillaries were so forcibly distended that they attained double their ordinary calibre, and by their numerous swellings and contractions resembled a knotted stick. The blood was generally stagnant, and the outlines of the separate particles could not be distinguished : the corpuscles could only be known from the discs by their whiteness. Over the whole surface of the tongue were numerous corpuscles outside of the vessels, and occasionally a few scattered discs. The extravasated blood-discs were rapidly altered: they appeared to lose their redness, and to become broken up into granules which soon disappeared. The corpuscles appeared to retain their form much longer. The engorged vessels became rapidly very irregular in their calibre, by the formation of numerous indentations or concavities throughout their length. Opposite these concavities were found one or more corpuscles which had escaped. The upper surface of the vessel likewise presented numerous dark spots of an irregular shape with very distinct dark edges. 'These were evidently small depressions or foramina seen in full, while the former were viewerl in profile. In some instances, the manner in which the corpuscle escaped from the interior of the tube could be distinctly followed : that part of the tube in contact with the external side of the corpuscle gradually disappeared, and at nearly the same time might be seen the formation of a distinct line of demarcation between the inner segment of the corpuscle and the fluid parts of the blood in contact with it. Any slight agitation then was capable of disengaging the corpuscle from the vessel to which it was now external, and in its place a concave depression remained, which appeared sufficiently protected by some membrane, as to oppose effectually the exit of the discs and the fluid parts of the blood. In rare instances the blood-discs and corpuscles might be seen separate and distinct within the tube, while occasionally some of the latter were seen to escape through the sides; the contents of the tube oscillating synchronously with the increased action of the blood in the surrounding vessels. In general, it is observed that the corpuscles escape more frequently at a bend or angle where there is a subdivision of the tube : those in the interior are also observed to collect there in greater numbers. In sone places, the indentures formed by the extravasated corpuscles were so deep that the vessel appeared to be quite disconnected; and such was sometimes really the case; but 
Phil:Mag: S.3. Vol:XXIX Pl.II

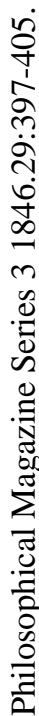
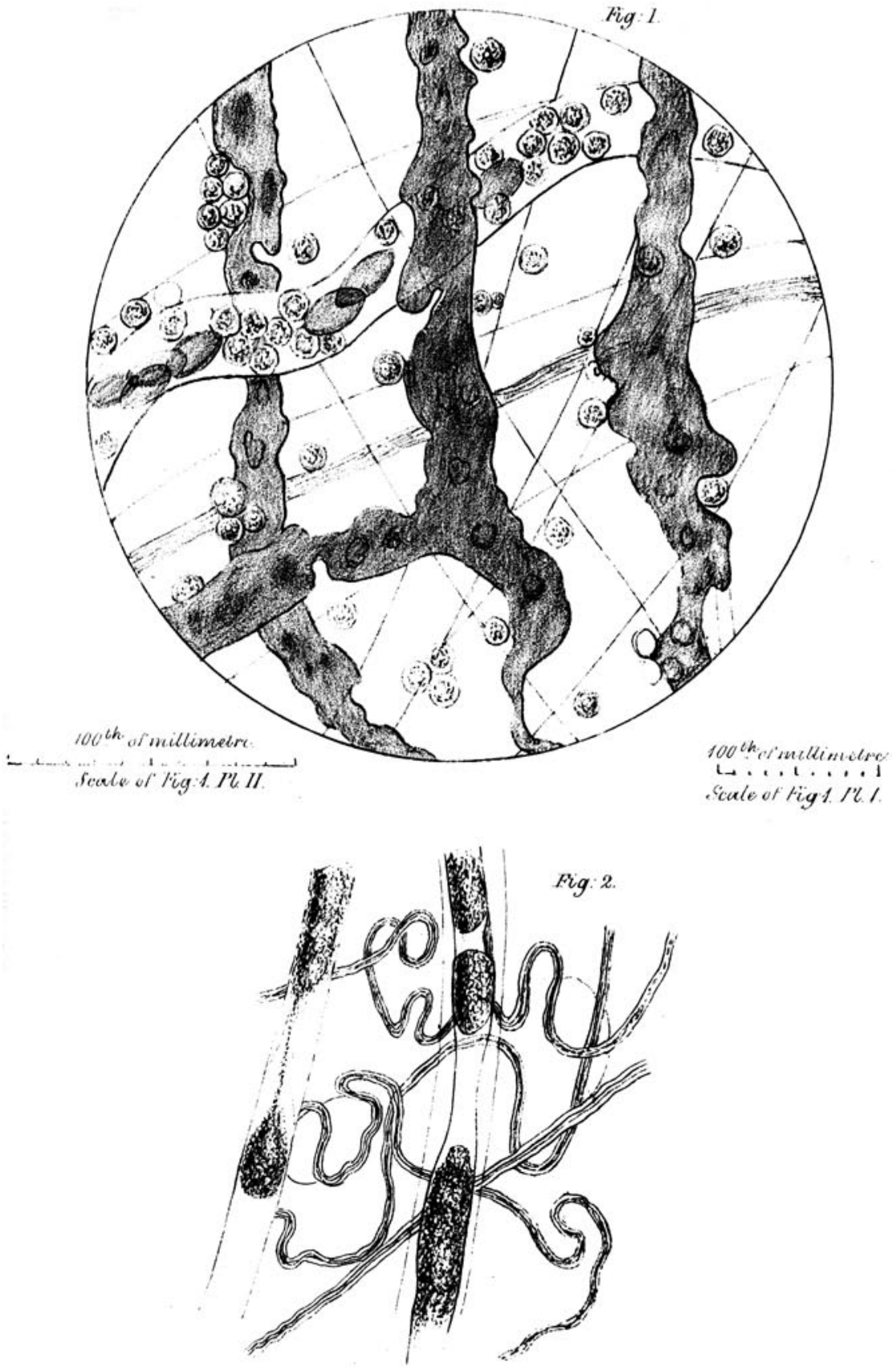
400 Dr. Waller on the Origin of Mucus and Pus-globules.

generally the diameter was only much decreased without being entirely disconnected, so as to interrupt the course of the blood. I have sometimes seen vessels of considerable size with an internal rapid current, the tubes of which at some places were contracted to one-fifth of the size which they presented elsewhere. It is easy to explain this, if we suppose that on some occasion they had been perforated by corpuscles and narrowed as I have described.

The corpuscles do not escape merely from vessels destitute of internal current. Capillaries with a most rapid current are often seen to be uneven, with slight indentations along their sides, and at a short distance external corpuscles which are more numerous opposite the indentations. In these cases, the various analogies visible with regard to the indentations and the corpuscles situated directly opposite to them outside the vessel, show that the vessel must have given them passage in the same manner as when the blood is stagnant or in a state of feeble oscillation. The larger trunks never present any distinct indentations to mark the passage of the corpuscle through them; but at their exterior corpuscles are frequently seen collected in abundance, which renders it probable that the parietes of these also may be dissolved to allow of the passage of these particles, which, however, must not be confounded with that condition which I have termed extra fibrination. A careful observer will easily distinguish the globular particles of what is probably condensed or coagulated fibrine, from the corpuscles, as they are much more minute and have no granular structure.

The results of other experiments performed in the same way are so similar to the above, that it would be a needless repetition to detail them. When an animated being is the subject, there must necessarily be some slight variation in the results. Thus in some of my observations I find a difference in the period which elapses before the injection and engorgement takes place, and the succeeding phænomena are likewise affected in proportion. I will briefly mention another observation, as it was attended with a loss of blood, and may serve in some respects to elucidate the influence of depletion on capillary circulation.

Obs. 2.-While the tongue of the frog was being secured, one of the trunks of the lingual vessel was ruptured near the jawbone and the blood escaped in abundance : from its dark colour and the continuous manner in which it flowed, a vein probably had been torn. The depletion thus produced represented on a small scale the operation of bleeding, to which we have such frequent recourse in medicine. 'To the naked eye the dis- 
tended membrane presented but a slight appearance of injection, in comparison to that which is exhibited by it in ordinary instances. The microscope showed that there existed scarcely a vessel containing stagnant blood. The venous and internal trunks were all considerably paler and more transparent than I had ever before seen them, and their outlines were distinctly marked, instead of that dull and indistinct appearance produced in ordinary cases by the extra fibrination or transudation of the liquor sanguinis. The circulation of the blood was extremely rapid in the trunks and capillaries, so much so as to render it impossible to detect the separate particles during their course. After the lapse of three or four hours the capillaries had become in a measure engorged with stagnant blood, but to a much less extent than usual. Many of the circulating papillæ were found to contain a central nucleus, completely black and opake, occupying the whole internal area, generally containing the vascular coil. Within this dark nucleus there appeared no circulation. In one of them, the passage of the blood particles could be traced from the point of entrance on one side to the dark nucleus, and from thence to the opposite extremity of the vessel. Most of the papillæ in this subject presented this appearance; in a few other papillæ the vascular coils existed as usual. I have met with papillæ of the same appearance in numerous other instances. After the engorgement of the capillaries had continued some time, the usual signs of the escape of the corpuscles were to be detected, and they were seen diffused over various parts of the membrane mingled with blood-discs, arising from the ruptured vessel. In other experiments, where no such loss of blood occurred, the tongue became entirely covered with corpuscles, without any admixture of blooddiscs.

While engaged in the examination of the same animal I made a few observations upon the muscular striæ, which I here mention, as they were very distinctly seen without any further preparation of the organ. The fibres of the genioglossus appeared perfectly round and cylindrical, with very perfect transverse markings, the direction of which varied in the same fibre on altering slightly the focus of the instrument, thereby indicating that at different depths the striæ had different directions. At the extremity of the tongue the fibres no longer presented this rounded appearance, but seemed perfectly flat. The transverse stria at this place did not appear to be confined within separate cylinders, but the whole surface was covered with muscular striæ and with dark parallel lines, indicating the presence of muscular fibres. The entire Phil. Mag. S. 3. Vol. 29. No. 195. Nov. 1846. 2 E 
surface thus appeared to be of a muscular nature. The most ready and correct representation of these diffused striæ, is by covering a piece of paper with prints of the papillæ of the top of the finger, which has been previously rubbed over with a little printer's ink, in other words, making finger-marks on the paper; when, by drawing parallel lines among these printed papillæ, a most faithful image is obtained.

With regard to other appearances presented by the capillaries, they will be found described in my former communication.

Those who have patience to watch for several hours the phænomena which occur in the capillaries, will perceive the great increase that takes place in the diameters of those under the influence of prolonged irritation, particularly at the edges nearest the irritating agents employed to secure the organ. After watching these changes, it will be seen how slight a cause, such as a temporary obstruction of a vessel by a few globules, is sufficient to determine whether the increase in volume shall be confined to one vessel or be divided among two or more. Therefore we can readily comprehend how the same causes in operation on the embryo may create all those anomalies observed in the distribution of the aortic trunks in the adult, which may be found represented in Bourgery's plates.

In endeavouring to account for the fact of the pnssage of the corpuscles through the vessels we find considerable difficulties. It cannot be referred to the infuence of vitality, as it is observed likewise to take place after death. It may be surmised, either that the corpuscle, after remaining a certain time in contact with the vessel, gives off by exudation from within itself some substance possessing a solvent power over the vessel, or that the solution of the vessel takes place in virtue of some of those molecular actions which arise from the contact of two bodies; actions which are now known as exerting such extensive influence in digestion, and are referred to what is termed the catalytic power.

While advancing these hypotheses we must not omit to bear in mind, that corpuscles nie constantly seen adherent, for a long space of time, to the inner sides of a vessel without altering their appearance in the least*.

Mucus.-In ordinary circumstances, the mucus which is formed on the tongue of the frog contains no particles in suspension, but entirely consists of a thick viscous substance,

* Acetic acid applied to an engorged vessel on the living tongne will dissolve the outer vesicle of the blood-disc and leave the nicleus completely uncovered, in the same way as when the blood is out of the vessels. The action of the acid is almost immediate. 
completely transparent. After prolonged irritation, however, as in the above-mentioned experiments, when corpuscles are seen diffused over the tongue, such is no longer the case; and numerous corpuscles are then found in the mucus which exists there, and which then possesses all the characters of the substances which are thrown off from the irritated mucous membranes of the human subject. It would be unnecessary to adduce any further evidence of the common origin of these two kinds of mucus, or rather of the globules which they contain.

Purulent matter:-Although the formation of purulent matter itself has not been included in the present observations, (this subject requiring a separate examination, which I will defer to a future occasion, ) the presence of its most general and constant ingredients, viz. the purulent globules and the fibro-albuminous fluid which contains them, may easily be explained by the preceding observations, in which the extra fibrination, corpusculation, and the extra corpusculation of the vessels, represent on a small scale all the principal phænomena accompanying its formation.

Absorption. - After having shown the manner in which the capillaries, engorged with stagnant blood, give off the corpuscles which they contain, it now remains to examine how they are enabled to discharge the rest of their contents. When these contents consist of blood in a fluid state, we can readily understand how, after the removal of the irritation, the engorgement would gradually cease, as is constantly observed with regard to vessels in this state. But many of these vessels, particularly those which have given off corpuscles, contain blood which appears to consist of a gelatinous mass, and is probably in a state of coagulation. The most simple notion of hydrodynamics shows the difficulty of driving a material of a semi-solid consistency through a delicate elastic tube. The question then arises as to the process by which these vessels discharge their contents and become again capable of conveying the blood to the parts which depend upon them for their nutrition. The following observations will in a great measure answer this question.

The frog of Obs. 1, after being kept twenty-four hours in water, was examined. The tongue, at first of its natural colour, became gradually injected, and presented the same appearances as were observed on the preceding day, with respect to the circulation and the escape of the corpuscles from the vessels. But in addition tubes were perceived in numerous places, containing an amorphous, colourless and nearly transparent substance, incompletely filling the cylindrical cavity 2 E 2 
which contained it. Many of these tubes appeared interrupted, and their course could only be traced by means of disjointed fragments containing the amorphous matter, which, under the highest magnifying power, appeared to consist of numerous irregular fragments loosely packed, and presenting a very considerable surface. Capillaries which contain recently coagulated blood are known to present a granulated, uneven appearance, caused by the irregular arrangement of the blood within them. The tubes were therefore the engorged capillaries of the previous day, which had been deprived of their colouring matter and some of their fluid contents by a chemical action, which is generally termed absorption; while other parts, not quite so easily acted upon, were not yet removed. The size of these granular tubes corresponded with the ordinary diameters of the capillary vessels and their trunks. Their direction likewise was the same as that pursued by vascular trunks and capillaries. Blood-vessels of about the same size could generally be seen at their sides, with an internal current of blood: some of these were probably of recent formation. The other tissues were in their usual condition: thus the muscles presented their characteristic striæ very distinctly; the nervous trunks and fibres were unimpaired; and the ramifications of the cellular fibres were also intact.

The subject of Obs. 2 was examined after the same lapse of time; the organ had nearly recovered its natural colour previous to this second examination. Numerous tubes with their amorphous contents were seen at different parts in exactly the same condition as mentioned above. The papille with the dark centre, as before described, were in the same state as the day before: small portions of muscular fibre were perceived, with their striæ lacerated and broken. The other tissues were unaltered.

Kensington, Oct. 15, 1846.

\section{EXPLANATION OF PLATES.}

PLATE I.

Fig. 1. Represents the dorsum of the frog's tongue covered with numerous papillæ, two of which are circular, and contain vascular coil connected with capillary vessels. These papillæ ure intimately connected with the perception of taste, and are analogous with the fungiform papillæ of the mammiferæ. The other papillæ represented are destitute of internal circulation, and much more irregular in form, and correspond to the filiform or conical papilla of the mammiferæ. The whole drawing is covered with scales of epithelium, amongst which are occasionally seen what appear to be small foramina, but which did not exist in this case.

Fig. 2. A fungiform or neuro-vascular papilla, as seen under a higher magnifying power. Within it is the vascular area. The external zone presents the radiated appearance which is sometimes seen. 


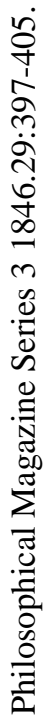

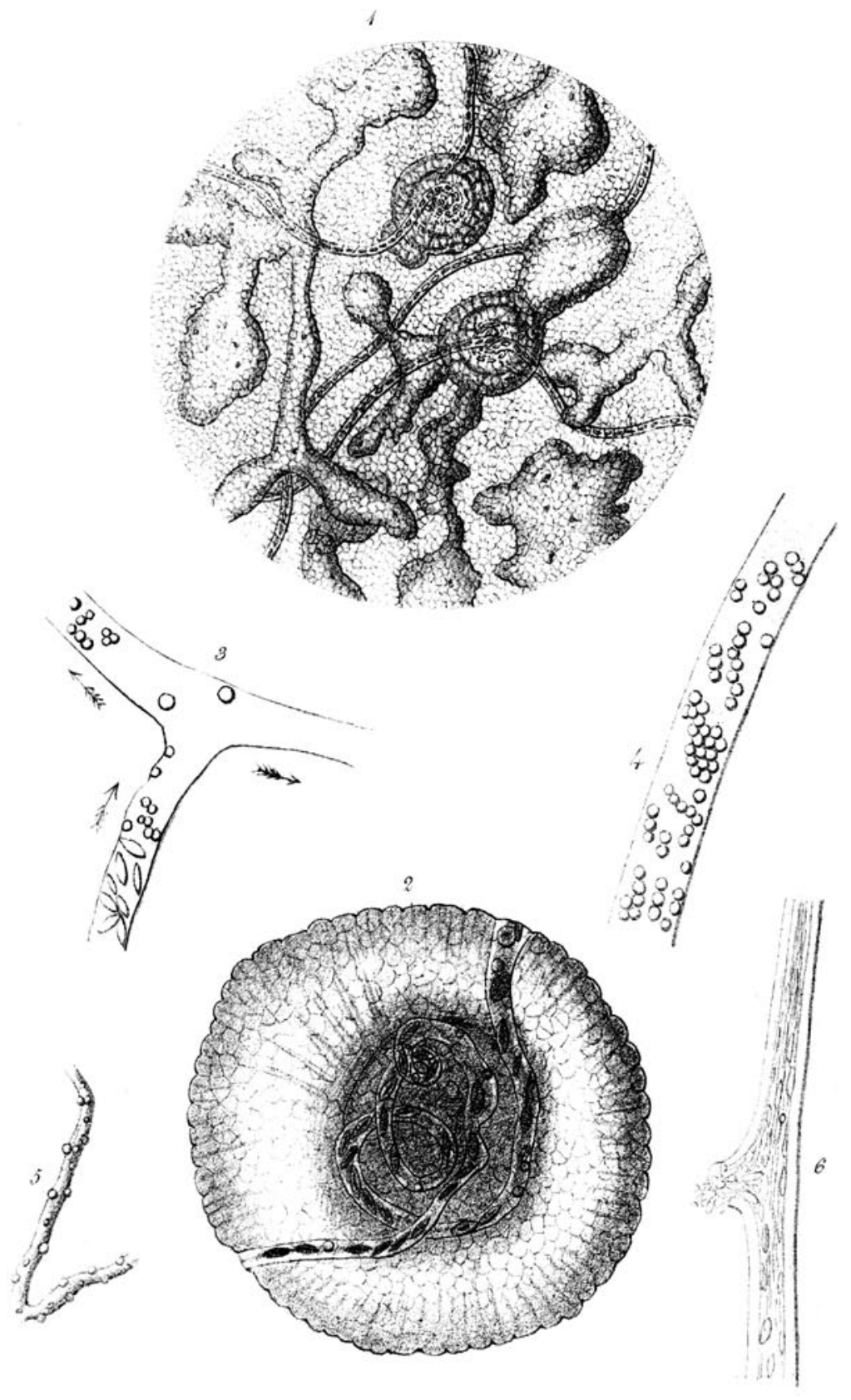


Fig. 3. Blood-discs and corpuscles with a capillary ; some of the latter near the sides were inspected for a long time, and remained fixed in the same situation, while a rapid current was traversing the vessel.

Fig. 4. Corpusculation of a vessel towards the end of the tongue. This vessel was traced for a considerable distance and contained no blood-discs.

Fig. 5. Extra fibrination of a vessel. The smaller globules are probably globular particles of fibrine, the others are extravasated corpuscles.

Fig. 6. Varicose swelling of a ruptured capillary giving passage to the blood. In the same subject were perceived similar swellings, but without a rupture, in which the blood circulated.

\section{PLATE II.}

Fig. 1. Represents vessels of the inferior surface of the tongue as they appear after the escape of the corpuscles, filled with stationary blood, deformed and indented at the points of escape, near which the corpuscles are generally found. A portion of a vessel with an internal current is likewise seen with discs, atid internal and external corpuscles. No indentations are seen near these, probably from the force of the current, which directly restored the form of the vessel. The remainder of this figure was covered with membranous muscular strix, which to avoid complication are not represented.

Fig. 2. Shows the process of absorption of stagnant blood. In this case the vessels themselves still remain, while their contents are unequally absorbed. Tortuous vessels ramify among them.

\section{IIX. Proceedings of Learned Societies.}

\section{ROYAL SOCIETY.}

[Continued from p. 133.]

June 18, "T THE Electric Fluid." By W. F. Stevenson, Esq.,

The author denies the existence of two electric fluids, and maintains that all the phenomena are explicable on the hypothesis of a single fluid; which when present in a conducting body renders it positive, and in a non-conducting body, negative; but a body which is naturally a conductor, may, he asserts, be rendered otherwise, by changing its form.

"Observations of the Heights of the Thermometer and Barometer made at Lenham Lodge, near Maidstone, Kent, during the first nine days of the month of June 1846." By George Hunsley Fielding, M.D., F.R.S.

On Sunday the 7 th of June 1846, the thermometer in the shade rose to the extraordinary height of $94^{\circ}$ Fahr., exceeding by one degree the heat of the 13th of July 1808, which was considered to be the highest on record in this country.

"On the relative dynamic value of the Degrees of the Compass; and on the Cause of the Needle resting in the Magnetic Meridian." By Sir Graves C. Haughton, K.H., M.A., F.R.S., Foreign Associate of the Institute of France. 